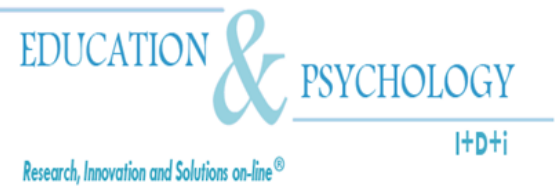

\title{
Volitional Regulation and Self-regulated Learning: An Examination of Individual Differences in Approach-Avoidance Achievement Motivation
}

\section{Jared M. Bartels ${ }^{1}$, Susan Magun-Jackson ${ }^{2}$, Arthur D. Kemp ${ }^{1}$}

${ }^{1}$ Psychology Department, University of Central Missouri, Warrensburg, MO ${ }^{2}$ Department of Counseling, Educational Psychology and Research, University of Memphis, Memphis, TN

USA

Correspondence: Jared M. Bartels. Psychology Department, Lovinger 1201. University of Central Missouri. Warrensburg, MO 64093. USA. E-mail: bartels@ucmo.edu 


\begin{abstract}
Introduction. In the present study we examined the differences in volitional strategy use (i.e., self-efficacy enhancement, negative-based incentives, and stress-reducing actions) and their relation to cognitive self-regulated learning strategy use (i.e., rehearsal, elaboration, organization, and critical thinking) in a sample of university students. Additionally, we tested the potential for approach-avoidance achievement motivation to moderate the relationship between volitional strategies and cognitive strategies.
\end{abstract}

Method. Participants were 141 undergraduate students from a large urban University located in the Mid-Southern United States.

Results. Results indicated that approach motivated individuals utilized self-efficacy enhancement and stress-reducing actions more often than avoidance motivated individuals. Regression analyses revealed approach-avoidance motivation to be a significant predictor of elaboration and organization while the volitional strategy of self-efficacy enhancement emerged as a significant predictor of rehearsal and elaboration strategies. Approach-avoidance motivation did not moderate this relationship.

Discussion and Conclusion. The present investigation highlights the important role approach-avoidance motivation plays in the cognitive and volitional regulatory abilities of the learner. Courses have been designed that effectively teach students self-regulated learning skills, and the present results suggest that the modeling of self-regulatory strategies in such courses is particularly important for avoidance motivated students.

Keywords: Need for achievement. Fear of failure. Volition. Self-regulated learning. Achievement goals.

Received: 01/09/09 Initial Acceptance: 01/12/09 Final Acceptance: 04/17/09 


\title{
La regulación volicional y la autorregulación del aprendizaje: un estudio de las diferencias individuales en la motivación de logro aproximación-evitación
}

\begin{abstract}
Resumen
Introducción. En este trabajo examinamos las diferencias en la utilización la regulación volicional (mejora de la autoeficacia, incentivación negativa, y reducción del estrés) y su relación con el aprendizaje autorregulado (práctica, elaboración, organización, y pensamiento crítico) en una muestra de estudiantes universitarios. Además, evaluamos el potencial de la motivación de logro aproximación-evitación para moderar la relación entre las estrategias volicionales y las cognitivas.
\end{abstract}

Método. Los participantes fueron 141 estudiantes de una Universidad próxima al sur de los Estados Unidos.

Resultados. Los resultados señalan que la aproximación motiva a los individuos relativamente a la autoeficacia y a utilizar actividades para reducir el estrés con más frecuencia que los sujetos con una motivación de evitación. Los análisis de regresión revelan que la motivación de logro aproximación-evitación puede ser un predictor significativo de la elaboración y de la organización, mientras que la estrategia volicional de autoeficacia aparece como un significativo predictor de las estrategias de práctica y elaboración. La motivación de aproximaciónevitación no modera la anterior relación.

Discusion y Conclusiones. La investigación destaca la importancia del papel que la motivación de aproximación-evitación juega sobre las habilidades cognitivas y de autorregulación del estudiante. Los cursos han sido diseñados para enseñar a los estudiantes habilidades de aprendizaje autorregulado, y los resultados obtenidos sugieren que el modelado de estrategias de autorregulación es particularmente importante para los estudiantes con motivación de evitación.

Palabras Clave: Necesidad de logro, miedo al fracas, volición, aprendizaje autorregulado, logro de objetivos.

Recibido: 09/01/09 Aceptación inicial: 12/01/09 Aceptación final: 17/04/09 


\section{Introduction}

Volitional control involves the use of strategies aimed at regulating emotions, motivation, and cognition in the processes of goal striving (Corno, 1993; Corno \& Kanfer, 1993; Kuhl, 1987; Kuhl, 2000; see also Wolters, 2003). Volition, according to Corno (1993), is conceptually and functionally distinct from motivation in that, while motivation is necessary to set goals and select strategies appropriate for attaining them, volition is necessary to protect against the abandonment of goals and serves to maintain effort and persistence when competing goals are present. In her model, Corno distinguishes between motivational control strategies aimed at the enhancement of goal-striving effort and persistence and emotional control strategies enacted to quell anxiety which may disrupt performance. Building off this model, McCann and collegues (McCann \& Garcia, 1999; McCann \& Turner, 2004) have specified several volitional strategies (measured by the Academic Volitional Strategies Inventory) commonly invoked in the process of maintaining task engagement and effort in an achievement context. These strategies include: positive thoughts as to one's competence or selfefficacy (i.e., self-efficacy enhancement), actions which reduce anxiety (i.e., stress-reducing actions), and thoughts that make one aware of the intrapersonal and interpersonal consequences of failure (i.e., negative-based incentives). Students, for example, in order to enhance or maintain motivation, may think about their goals, past successes and ability to succeed (selfefficacy enhancement), they may focus on the disappointment of important others upon poor performance (negative-based incentives), or they may imagine a successful performance as a means of alleviating anxiety (stress-reducing actions).

Within a broader achievement motivation context, research has demonstrated (1) the influence of academic achievement goals with respect to the utilization of volitional strategies and (2) the association between volitional strategies and cognitive self-regulated learning strategies or strategies aimed at facilitating the processing of to-be-learned material (Bembenutty, 1999; Garcia, McCann, Turner, \& Roska, 1998; McCann \& Turner, 2004; Wolters, 1998; Wolters, 1999; Wolters, 2004; Wolters \& Rosenthal, 2000). Achievement goals are distinguished in terms of how competence is defined (task-defined or normativedefined) and in terms of valence (approach or avoidance; Elliot \& McGregor, 2001). Within this model, goals aimed at the attainment of task-defined and normative-defined competence represent mastery-approach and performance-approach goals, respectively. On the other hand, goals aimed at the avoidance of task-defined and normative-defined competence represent mastery-avoidance and performance-avoidance goals, respectively, (Thrash \& Hurst, 2008). 
With respect to their relation to volition, Bembenutty (1999), for example, found masteryapproach goals (i.e., task-oriented goals aimed at learning as much as possible in class) to be positively associated with the use of self-efficacy enhancement strategies, while performanceavoidance goals (i.e., goals focused on the avoidance of looking dumb in class) were negatively associated with the volitional strategy of negative-based incentive use. Additionally, McCann and Turner (2004) found volitional strategies to be significantly correlated with cognitive strategy use (i.e., or rehearsal strategies, elaboration, organization, and critical thinking).

While it has been suggested that volitional strategies serve a facilitative role with respect to cognitive strategy use (e.g., Garcia, McCann, Turner, \& Roska, 1998), there may be individual differences in the overall use and effectiveness of volitional stategies. As noted, previous research suggests differences in volitional strategy use at the achievement goal level. These differences, for example, may indicate that a student adopting a goal of mastering course material may utilize different volitional strategies that the student approaching a course with the goal of outperforming others. Moreover, researchers have posited disparate volitional strategy use at the dispositional achievement motivation (i.e., need for achievement and fear of failure) level as well (Baumann, Kaschel, \& Kuhl, 2007; Kehr, 2004; Thill \& Curry, 2000). That is, individual differences may exist in the approach-avoidance motivation of students which influence the goals that students adopt.

Need for achievement and fear of failure represent differential sensitivity to experience pride in success and shame with failure, respectively (Birney, Burdick, \& Teevan, 1969; McClelland, Atkinson, Clark, \& Lowell, 1953; McGregor \& Elliot, 2005). These motives are engendered by the association of affection upon success and neutral response to failure (need for achievement), and scorn/punishment upon failure and a neutral response to success (fear of failure) early in childhood (Birney et al., 1969). Furthermore, these dispositional approachavoidance constructs antecede achievement goal adoption (Conroy \& Elliot, 2004; Elliot \& Church, 1997; Elliot \& McGregor, 1999; Elliot \& McGregor, 2001; for a review see Elliot, 1997). In other words, achievement goals represent a more proximal expression of dispositional achievement motives (Elliot \& Church, 1997). Thus, need for achievement is associated with striving to attain task-defined (i.e., performance-approach-goal). Fear of failure, on the other hand, is associated with the adoption of normative-defined success (i.e., performanceapproach goal), while fear of failure is associated with the adoption of goals aimed at the avoidance of incompetence (i.e., mastery-avoidance and performance-avoidance goals) at worst, and the attainment of normative-defined success (i.e., performance-approach goals) at 
best. However, to date, studies have largely focused on achievement goals with respect to volition; research is needed to examine potential differences in volitional strategy use at the dispositional level of motivation. The relevance of such research is grounded in the aforementioned relationship between dispositional motivation and goals. Achievement goals are the more proximal and malleable form of achievement motivation. In light of this, it may be suggested that altering student goals should be the target of interventions aimed at combating maladaptive motivation in schools. However, experimental studies have shown interventions aimed at dispositional motivation (e.g., fear of failure) to be effective as well (Stamps, 1973). If, as Elliot and Church (1997) note, achievement goals represent "concrete manifestations" of dispositional motivation, then reducing fear of failure may be the more appropriate focus of such interventions.

\section{The Present Study}

While some researchers have proposed a facilitative role of volition with respect to cognitive self-regulated learning strategy use (Garcia et al., 1998), others have questioned the view of volition as equivocally adaptive (e.g., Corno, 2004). It may be that volitional strategies are facilitators of cognitive strategy use for the approach motivated individual, but not for the avoidance motivated individual. Specifically, we will examine mean differences in the volitional strategies of self-efficacy enhancement, negative-based incentives, and stressreducing actions among approach and avoidance motivated individuals. We hypothesize that those individuals who are approach motivated will utilize volitional strategies to a greater extent than those who are avoidance motivated. Avoidance motivated individuals (i.e., those high in fear of failure) are quick to disengage or withdraw effort in a task when experiencing difficulty (Birney et al., 1969), motivational or otherwise, and thus, we expect them to utilize each of the volitional strategies aimed at maintaining task persistence.

The second purpose of this study is to explore the relationship between volitional strategy use and cognitive strategy use among approach motivated and avoidance motivated individuals. Specifically, we will examine the potential for approach-avoidance motivation to moderate the relationship between volitional strategies and cognitive ones. For most students volitional regulation may lead to greater cognitive self-regulation, however, the high in fear of failure individual's ability to focus and self-regulate is constantly taxed by anxiety and abilityrelated concerns (Atkinson \& Feather, 1966). Those who fear failure prefer tasks that are extremely easy or extremely challenging (i.e., they avoid optimally challenging tasks); tasks that 
demand less effective use of motivation enhancing strategies. Moreover, recent research suggests that fear of failure is associated with less metacognitive awareness or knowledge of one's effective/ineffective application of self-regulatory strategies (Bartels \& Magun-Jackson, in press). Thus, we hypothesize that among those who fear failure, volitional strategies will not be associated with cognitive strategies.

\section{Method}

\section{Participants}

Participants were 141 undergraduate students from a large urban University located in the Mid-Southern United States. Participants ranged in age from 18 to $47(M=22.32, S D=$ 4.96). Year in school was as follows: freshman $n=21$ (14.9\%), sophomore $n=61(43.3 \%)$, junior $n=42(29.8 \%)$, and senior $n=17(12.1 \%)$. The gender and race composition of the present sample were as follows: female $n=126$; male $n=15$; African American $n=50$; Caucasian $n=87$; Hispanic $n=1$; Asian $n=1$; Other $n=2$. Participants were volunteers from courses within the College of Education at the University.

\section{Instruments}

Dispositional achievement motivation. Approach-avoidance achievement motivation was assessed using an updated version of the Success/Failure Questionnaire II (SFQII; Herman, 1990). The 14-item measure asks participants to indicate their level of agreement using a 5 point-Likert scale, $(1=$ strongly disagree; $5=$ strongly agree $)$ regarding questions pertaining to need for achievement (e.g., When I find myself in a situation where I am under great pressure, I try even harder and find that often do an outstanding job) and fear of failure (e.g., When I experience failure, I expect to receive punishment from someone). Thus, the measure yields a score for both the need for achievement (approach motivation) and fear of failure (avoidance motivation) subscales. The higher the score on both subscales indicates higher levels of need for achievement and fear of failure. Item analysis for each subscale revealed several items with low item-total correlations (i.e., below .30). After removal of these items, the need for achievement subscale included six items $(\alpha=.62)$, while the fear of failure subscale contained five items $(\alpha=.58)$.

Self-regulated learning strategies. Cognitive self-regulated learning strategies were assessed using the Motivated Strategies for Learning Questionnaire (MSLQ; Pintrich, Smith, Garcia, \& McKeachie, 1991). The MSLQ assesses the cognitive strategies of rehearsal (e.g., 
When I study for a class, I practice saying the material to myself over and over), elaboration (e.g., I try to apply ideas from course readings in other class activities such as lecture and discussion), organization (e.g., I make simple charts, diagrams, or tables, to help me organize course material), and critical thinking (e.g., I often find myself questioning things I hear or read in this course to decide if I find them convincing). Participants respond to the abovementioned items on a 7-point Likert scale $(1=$ not at all true of me; $7=$ very true of me). Reliability coefficients reported in the MSLQ manual are as follows: .69 for rehearsal, .76 for elaboration, .64 for organization, .80 for critical thinking. Cronbach alpha coefficients obtained in the present study were .68 for rehearsal, .74 for elaboration, .69 for organization (an item from the organization subscale was removed to improve reliability), and .78 for critical thinking.

Volitional strategies. Volitional strategy was assessed utilizing the Academic Volitional Strategies Inventory (AVSI; McCann \& Turner, 2004). The 20 item inventory, using a 7-point Likert-type scale ( 1 = not true of me, 7 = very true of me), assesses the frequency of volitional strategy use within academic contexts asking students to indicate their use of selfefficacy enhancement strategies (e.g., I think about my strengths and the resources I can draw on to help me with difficult assignments or test information), negative-based incentives (e.g., I think about the possible negative consequences of doing poorly in this class), and stress reducing actions (e.g., I usually meditate or use some method of relaxation so I am better able to concentrate on my studies). Reliabilities among the present sample were as follows: selfefficacy enhancement $(\alpha=.72)$ and negative-based incentives $(\alpha=.70)$. Consistent with results reported by McCann \& Garcia (1999), and likely partially a function of the scale containing only five items (less than the negative-based incentives and self-efficacy enhancement), the reliability of the stress-reducing actions scale was .54.

Social Desirability Scale-short form. The Social Desirability Scale (Crowne \& Marlowe, 1960) measures socially desirable response bias. There are several reliable short forms of the original measure (see Reynolds, 1982). The 11-item short form A, utilized in the present study is reliable (Kuder-Richardson reliability of .74) and highly correlated with the original measure $(r=.91)$. Cronbach alpha reliability of this short form among the present sample was .69.

Ability. Self-reported grade point average (GPA) served as an estimate of ability. While the present study utilized self-reported GPA, previous research indicates that institutional GPA is an adequate proxy for ability relative to others (e.g., SAT scores; Grove, Wasserman, \& Grodner, 2006). 


\section{Procedure}

Instructors of the surveyed courses within the College of Education were contacted to obtain permission for participation in the study; participants were solicited from those courses in which instructors had given permission. Students who chose to volunteer completed an informed consent followed by the measures assessing approach-avoidance motivation, volitional strategy use, achievement goals, and social desirability (as well as other measures not utilized in the present study). The remaining measure assessing self-regulated learning strategy use was completed in class approximately one week later. Results of the present study were part of a larger study on self-regulated learning.

\section{Data analyses}

In order to ensure the appropriateness of parametric statistical analysis, the skewness and kurtosis of the present variables were examined via guidelines presented by Field (2005). None of the values were significant at the .01 level. All subsequent regression analyses were also conducted with the variables of interest centered in order to reduce multicollinearity (Aiken \& West, 1991). Multicollinearity was assessed via variance inflation factors (VIF; Draper $\&$ Smith, 2002). As per the recommendation of Freund and Wilson (1998; i.e., VIF < 10), multicollinearity was not significant in subsequent analyses.

In order to assess differences in volitional strategy use, a dichotomous variable was created categorizing individuals as approach and avoidance motivated. First, fear of failure scores were subtracted from need for achievement scores. Second, based on a median split $(M d n=1.20)$, these scores were categorized as approach motivated $(n=73)$ if above the median and avoidance motivated $(n=68)$ if below.

A Multivariate Analysis of Variance (MANOVA) was used to examine mean differences in the volitional strategies of self-efficacy enhancement, negative-based incentives, and stress-reducing actions among approach/avoidance motivated individuals. Multiple regression analyses were used to assess the potential moderation of approach-avoidance motivation with respect to volitional and cognitive strategy use. Separate regressions were run for each of the cognitive strategies (i.e., rehearsal, elaboration, organization, and critical thinking). Interaction terms were built by multiplying the approach-avoidance motivation variable with each of the volitional strategies. Grade point average and social desirability were also included in each regression to control for ability and socially desirable response bias. 
Table 1. Means, Standard Deviations, and Intercorrelations among Measures

\begin{tabular}{|c|c|c|c|c|c|c|c|c|c|c|c|c|c|}
\hline Measure & $M$ & $S D$ & 1 & 2 & 3 & 4 & 5 & 6 & 7 & 8 & 9 & 10 & 11 \\
\hline 1. $\mathrm{NACH}$ & 3.98 & 0.46 & - & - & - & - & - & - & - & - & - & - & - \\
\hline 2. $\mathrm{FOF}$ & 2.79 & 0.67 & $-.43 * *$ & - & - & - & - & - & - & - & - & - & - \\
\hline 3. Rehearsal & 4.85 & 1.26 & $.24 * *$ & -.04 & - & - & - & - & - & - & - & - & - \\
\hline 4. Elaboration & 4.84 & 1.10 & $.39 * *$ & .16 & $.40 * *$ & - & - & - & - & - & - & - & - \\
\hline 5. Organization & 4.65 & 1.48 & $.34 * *$ & $-.25 * *$ & $.53 * *$ & $.47 * *$ & - & - & - & - & - & - & - \\
\hline 6. Crit thinking & 3.90 & 1.27 & $.43 * *$ & $-.21 *$ & $.34 * *$ & $.55^{* *}$ & $.34 * *$ & - & - & - & - & - & - \\
\hline 7. Stress red & 3.89 & 1.14 & $.39 * *$ & -.11 & $.23 * *$ & $.25 * *$ & $.29 * *$ & $.22 * *$ & - & - & - & - & - \\
\hline 8. Neg inc & 4.65 & 1.22 & .03 & .15 & $.22 * *$ & .03 & $.20 * *$ & .10 & $.29 * *$ & - & - & - & - \\
\hline 9. Self-eff & 5.26 & 0.88 & $.37 * *$ & -.16 & $.45 * *$ & $.34 * *$ & $.38 * *$ & $.30 * *$ & $.54 * *$ & $.44 * *$ & - & - & - \\
\hline 10. Soc des & 5.99 & 2.58 & $.23 * *$ & $-.26 * *$ & .14 & .12 & $.18 *$ & .10 & $.28 * *$ & .03 & .14 & - & - \\
\hline 11. GPA & 2.98 & 0.52 & .16 & -.02 & -.08 & -.01 & .08 & -.04 & -.02 & -.17 & .03 & -.05 & - \\
\hline
\end{tabular}

Note. NACH $=$ Need for achievement; FOF $=$ Fear of failure; Stress red = Stress-reducing actions;

Neg inc $=$ Negative-based incentives; Self-eff $=$ Self-efficacy enhancement; Soc des = Social desirability $*=.05, * *=.01$. 


\section{Results}

Mean differences. Means and standard deviations for, and bivariate correlations among the present variables are displayed in Table 1. Significant differences in volitional strategies emerged between approach and avoidance motivated individuals, Wilk's $\Lambda=.88, F(3,137)=$ $6.24, p<.01, n_{p}{ }^{2}=.12$. Univariate analyses revealed significant differences in self-efficacy enhancement, $F(1,139)=8.72, p<.01$, and stress-reducing actions, $F(1,139)=13.25, p<$ .001. Approach-motivated individuals reported significantly greater use of self-efficacy enhancement $(M=5.47 / 5.04 ; S D=.89 / .82)$ and stress-reducing actions $(M=4.22 / 3.55 ; S D=$ 1.07/1.11) than avoidance-motivated individuals. However, the magnitude of the differences in self-efficacy enhancement (Cohen's $d=.17$ ) and stress-reducing strategies (Cohen's $d=$ .17) were small (Cohen, 1988). No significant differences emerged for negative-based incentives between approach motivated $(M=4.62 ; S D=1.29)$ and avoidance motivated $(M=4.67$; $S D=1.16$ ) individuals. Thus, approach-motivated individuals reported greater use of the volitional strategies of self-efficacy enhancement and stress-reducing actions but not negativebased incentives.

\section{Moderation of approach-avoidance motivation}

In order to assess the potential moderation of approach-avoidance motivation for the cognitive strategy of rehearsal, multiple regression analysis was conducted with volitional strategies, approach-avoidance achievement motivation, the interaction between each (i.e., approach-avoidance motivation x self-efficacy enhancement, approach-avoidance motivation $\mathrm{x}$ negative-based incentives, and approach-avoidance motivation $\mathrm{x}$ stress-reducing actions), as well as GPA and social desirability as predictors and the cognitive strategy of rehearsal as the criterion variable. The overall model was significant, $F(9,131)=4.46, p<.01, R^{2}=.23$. The results of the regression are displayed in Table 2. Self-efficacy enhancement emerged as the only significant independent predictor of rehearsal strategy use, $\beta=.63$. None of the interactions between approach-avoidance motivation and the volitional strategies were significant. 
Table 2. Regression Results for the Cognitive Strategy of Rehearsal

\begin{tabular}{lccccc}
\hline Variable & $B$ & $S E B$ & $\beta$ & $t$ & $p$ \\
\hline & & & & & \\
Approach-avoidance & -.04 & .21 & -.02 & -.21 & $\mathrm{~ns}$ \\
Self-eff & .91 & .22 & .63 & 4.19 & $<.001$ \\
Neg inc & -.04 & .14 & -.04 & -.28 & $\mathrm{~ns}$ \\
Stress red & -.16 & .14 & -.14 & -1.11 & $\mathrm{~ns}$ \\
App-Av x self-eff & -.43 & .29 & -.22 & -1.50 & $\mathrm{~ns}$ \\
App-Av x Neg inc & .08 & .18 & .06 & .43 & $\mathrm{~ns}$ \\
App-Av x Stress red & .22 & .21 & .14 & 1.07 & $\mathrm{~ns}$ \\
Soc des & .03 & .04 & .07 & .85 & $\mathrm{~ns}$ \\
GPA & -.21 & .19 & -.09 & -1.10 & $\mathrm{~ns}$
\end{tabular}

Note. Self-eff $=$ Self-efficacy enhancement; Neg inc = Negative-based incentives; Stress red = Stress-reducing actions; Soc des $=$ Social desirability; GPA $=$ Grade point average.

The aforementioned set of predictors was also entered into the model for the cognitive strategy of elaboration. The overall model was significant, $F(9,131)=3.67, p<.01, R^{2}=.20$. The results of the regression are shown in Table 3. Both approach-avoidance motivation, $\beta=$ .24 , and self-efficacy enhancement, $\beta=.31$ emerged as significant predictors of elaboration. In the light of the coding of approach-avoidance motivation (i.e., avoidance $=0$; approach $=$ 1) inspection of the regression coefficient indicates that elaboration scores for approach motivated individuals are significantly higher (i.e., .24 units) than those of avoidance motivated individuals. The interactions between dispositional motivation and volitional strategies were not significant. 
Table 3. Regression Results for the Cognitive Strategy of Elaboration

\begin{tabular}{lccccc}
\hline Variable & $B$ & $S E B$ & $\beta$ & $t$ & $p$ \\
\hline & & & & & \\
Approach-avoidance & .53 & .19 & .24 & 2.88 & $<.01$ \\
Self-eff & .39 & .19 & .31 & 2.02 & $<.05$ \\
Neg inc & -.18 & .13 & -.21 & -1.46 & $\mathrm{~ns}$ \\
Stress red & -.01 & .13 & -.01 & -.05 & $\mathrm{~ns}$ \\
App-Av x self-eff & -.01 & .26 & -.01 & -.05 & $\mathrm{~ns}$ \\
App-Av x Neg inc & .13 & .16 & .11 & .79 & $\mathrm{~ns}$ \\
App-Av x Stress red & .10 & .19 & .07 & .55 & $\mathrm{~ns}$ \\
Soc des & .00 & .04 & .00 & .03 & $\mathrm{~ns}$ \\
GPA & & & & & \\
\end{tabular}

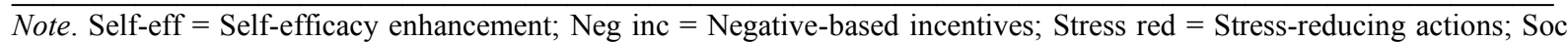
des $=$ Social desirability; GPA $=$ Grade point average.

The regression model for organization, the results of which are displayed in Table 4, was also significant, $F(9,131)=4.28, p<.01, R^{2}=.23$. Only approach-avoidance motivation emerged as a significant independent predictor of organization. As with elaboration this is in the expected direction. That is, organization scores are higher for approach motivated individuals than avoidance motivated individuals. Lastly, while the overall model for critical thinking was significant $F(9,131)=2.09, p<.05, R^{2}=.13$, none of the predictors explained a significant, unique portion of variance. The results of this regression are summarized in Table 5. As with the other cognitive strategies, the interactions between approach-avoidance motivation and volitional strategies were not significant. Thus, for each cognitive strategy, differences in approach-avoidance motivation did not result in significant differences in the relationship between volitional strategies and cognitive strategies. 
Table 4. Regression Results for the Cognitive Strategy of Organization

\begin{tabular}{lccccl}
\hline Variable & $B$ & $S E B$ & $\beta$ & $t$ & $p$ \\
\hline Approach-avoidance & .63 & .25 & .21 & 2.56 & $<.05$ \\
Self-eff & .35 & .26 & .21 & 1.37 & $\mathrm{~ns}$ \\
Neg inc & -.00 & .17 & -.00 & -.01 & $\mathrm{~ns}$ \\
Stress red & -.01 & .17 & -.01 & -.07 & $\mathrm{~ns}$ \\
App-Av x self-eff & .14 & .34 & .06 & .42 & $\mathrm{~ns}$ \\
App-Av x Neg inc & .19 & .21 & .18 & .87 & $\mathrm{~ns}$ \\
App-Av x Stress red & .12 & .24 & .07 & .51 & $\mathrm{~ns}$ \\
Soc des & .05 & .05 & .09 & 1.05 & $\mathrm{~ns}$ \\
GPA & .26 & .23 & .09 & 1.13 & $\mathrm{~ns}$
\end{tabular}

$\overline{\text { Note} .}$. Self-eff $=$ Self-efficacy enhancement; Neg inc = Negative-based incentives; Stress red = Stress-reducing actions; Soc des $=$ Social desirability; GPA $=$ Grade point average.

Table 5. Regression Results for the Cognitive Strategy of Critical Thinking

\begin{tabular}{lccccc}
\hline Variable & $B$ & $S E B$ & $\beta$ & $t$ & $p$ \\
& & & & & \\
\\
Approach-avoidance & .26 & .22 & .10 & .15 & $\mathrm{~ns}$ \\
Self-eff & .39 & .23 & .27 & 1.68 & $\mathrm{~ns}$ \\
Neg inc & -.17 & .15 & -.16 & -1.11 & $\mathrm{~ns}$ \\
Stress red & .02 & .15 & .02 & .15 & $\mathrm{~ns}$ \\
App-Av x self-eff & .00 & .31 & .00 & .00 & $\mathrm{~ns}$ \\
App-Av x Neg inc & .22 & .20 & .16 & 1.10 & $\mathrm{~ns}$ \\
App-Av x Stress red & .07 & .22 & .04 & .32 & $\mathrm{~ns}$ \\
Soc des & .01 & .04 & .02 & .22 & $\mathrm{~ns}$ \\
GPA & -.13 & .21 & -.05 & -.61 & $\mathrm{~ns}$
\end{tabular}

Note. Self-eff $=$ Self-efficacy enhancement; Neg inc $=$ Negative-based incentives; Stress red = Stress-reducing actions; Soc des $=$ Social desirability; GPA $=$ Grade point average. 


\section{Discussion}

The present results, in part, substantiate the hypothesis that individual differences in approach-avoidance achievement motivation is associated with differences in the utilization of volitional strategies or strategies aimed at the sustenance of motivation in academic tasks. Specifically, approach motivated individuals reported greater utilization of self-efficacyenhancement strategies and stress-reducing actions than avoidance motivated individuals. These results extend the extant understanding of the relationship between achievement motivation at the goal level and volitional strategy use to achievement motivation at the dispositional level. The latter being the motivational antecedent to achievement goals (Elliot \& Church, 1997). Specifically, as noted, need for achievement has consistently been associated with the adoption of mastery-approach goals, while performance-avoidance goals are "energized" by fear of failure (Conroy \& Elliot, 2004; Elliot \& Church, 1997; Elliot \& McGregor, 1999; Elliot \& McGregor, 2001; Van Yperen, 2006). In light of this, our finding that approach motivated individuals report greater use of self-efficacy enhancement is consistent with the greater reported use of such strategies among those adopting mastery-approach goals (Bembenutty, 1999; Wolters \& Rosenthal, 2000). However, while Bembenutty found performance-avoidance goals to be associated with negative-based incentive use, we found no significant differences in such strategies between approach and avoidance motivated individuals.

The current findings suggest self-efficacy enhancement strategies to be more often utilized by individuals optimally motivated (i.e., approach-oriented). Self-efficacy represents an individual's judgment as to "their capabilities to organize and execute courses of action required to attain designated types of performance" (Bandura, 1986, p. 391). Self-efficacy is positively associated with intrinsic interest, academic performance and persistence (Chemers, Hu, \& Garcia, 2001; Multon, Brown, \& Lent, 1991), as well as self-regulated learning strategy use (Zimmerman, 2000). Thus, low self-efficacy negatively impacts effort and persistence and ultimately performance. As Bandura (1986) notes, "people are disinclined to strive for rewards requiring performances they judge themselves incapable of attaining, nor do they passionately aspire to goals they judge they can never fulfill” (p. 430-431). While genuine self-efficacy may not be developed via self-efficacy enhancement strategy use, such strategies may serve to bolster task-relevant self-efficacy and thus serve as a motivational scaffold.

Such results are also disconcerting in light of what is known about the avoidance motivated student or the individual high in fear of failure. First, fear of failure has been found to 
be negatively associated with general self-efficacy (Bartels, 2007). The interrelationship between fear of failure, self-efficacy and volition is evident in Atkinson and Feathers' (1966) description of the "failure threatened personality". They note, "He [the individual high in fear of failure] would never voluntarily undertake an activity requiring skill where there is any uncertainty about the outcome" (p. 369). Thus, the student in greater need of self-efficacy enhancing strategies in his/her self-regulatory repertoire is the student, as the present results suggest, less likely to use them (relative to approach motivated students). Second, in light of the temperamental and personalogical basis of fear of failure (i.e., negative affectivity and neuroticism, respectively; Gable, Reis, \& Elliot, 2003), stress-reducing actions also appear to be strategies that would be of particular use to the individual high in fear of failure (i.e., avoidance motivated). Anxiety in an achievement context is the hallmark of fear of failure (Atkinson \& Feather, 1966). Thus, coping with the stress inherent in the evaluative situation (where the threat of failure is salient) is a priority for such an individual.

Regression analyses further indicated that approach-avoidance motivation and selfefficacy enhancement emerged as significant predictors of two of the four cognitive strategies (i.e., elaboration and organization). Elaboration represents a strategy (e.g., creating analogies) aimed at integrating new information with existing knowledge (Pintrich, Smith, Garcia, \& McKeachie, 1993; Weinstein \& Mayer, 1986). Similarly, organizational strategies represent attempts to manipulate and organize information in order to facilitate learning.

Contrary to our hypothesis, none of the interaction terms were significant, suggesting that individual differences (with respect to achievement motivation) do not moderate the relationship between volitional strategy use and cognitive strategy use. A study by Thill and Cury (2000) may shed light on why such differences failed to emerge. The authors found social comparison goals (similar to performance-approach goals) to be associated with greater distraction and anxiety during a task and the utilization of strategies to control intrusive thoughts. Thus, the results obtained by Thill and Cury suggest that individuals adopting such goals more often experience distracting, intrusive thoughts during a task, and thus more often utilize strategies to control such thoughts. It may be that the avoidance motivated individual (i.e., high in fear of failure) more often utilizes these strategies (to control intrusive thoughts) which in turn interfere with the use of both motivational and cognitive regulation strategies. We did find less use of both of these strategies among avoidance-motivated individuals in the present study; however, future research is needed to confirm the hypothesized role (i.e., interference) of strategies to control intrusive thoughts. 
Overall, such results are encouraging suggesting that if in their self-regulatory arsenal, these volitional strategies may be equally effective for the avoidance motivated individual. Our results do not contradict the proposed facilitative role of volitional strategies with respect to cognitive self-regulation. Interventions aimed at fostering volitional strategy use may be equally effective at maintaining effort and persistence in academic task and in turn the use of cognitive strategies. However, the current study does not warrant such an interpretation and further research is needed to substantiate this proposed causal relation.

A notable limitation of the present study is the limited generalizability with respect to the small and primarily female sample. Likewise, the exclusive use of self-report measures may be seen as a limitation; structured interview protocols, for example, offer an alternative means of assessing self-regulated learning strategies (e.g., see Ley \& Young, 1998). Therefore, future studies should include alternative means of assessment not only for self-regulation (e.g., structured interviews) but for approach-avoidance achievement measures as well (e.g., projective measures). Overall, the present results suggest individual differences at the dispositional achievement motivation level in the use of volitional and cognitive self-regulated learning strategies. However, these individual differences in approach-avoidance motivation did not influence the association between volition strategies and cognitive strategies.

Successful students effectively self-regulate their learning; this includes having an array of cognitive, behavioral, and volitional strategies at the student's disposal (Pintrich, 2004). Research suggests courses designed to teach self-regulated learning strategies may be effective at improving academic performance (e.g., Eissa, 2009; Tuckman, 2003; for a review of self-regulated learning intervention see Torrano \& González, 2004). Moreover, Trawick \& Corno (1995) describe the successful implementation of a program teaching volitional control to community college students. The Academic Volitional Strategies Inventory (McCann \& Turner, 2004), utilized in the current study, can serve as an assessment tool and thus may provide a basis for developing effective interventions or courses to develop such skills. The present research suggests that such interventions are particularly important for the avoidancemotivated student; a student struggling with anxiety and self-doubt and thus in the greatest need of having, within the student's self-regulatory repertoire, volitional strategies aimed at countering both. 


\section{References}

Aiken, L. S., \& West, S. G. (1991). Multiple regression: Testing and interpreting interactions. Newbury Park, California: Sage Publications.

Atkinson, J. W., \& Feather, N. T. (Eds.). (1966). A theory of achievement motivation. New York: John Wiley and Sons.

Bartels, J. M. (2007). Dispositional positive and negative affect and approach-avoidance achievement motivation. Individual Differences Research, 5, 246-259.

Bartels, J. M., \& Magun-Jackson, S. (in press). Approach-avoidance motivation and metacognitive self-regulation: The role of need for achievement and fear of failure. Learning and Individual Differences.

Bandura, A. (1986). Social foundations of thought and action: A social cognitive theory. Englewood Cliffs, NJ: Prentice-Hall Inc.

Baumann, N., Kaschel, R., \& Kuhl, J. (2007). Affect sensitivity and affect regulation in dealing with positive and negative affect. Journal of Research in Personality, 41, 239-248.

Bembenutty, H. (1999). Sustaining motivation and academic goals: The role of academic delay of gratification. Learning and Individual Differences, 11, 233-257.

Birney, R. C., Burdick, H., \& Teevan, R. C. (1969). Fear of failure. New York: Van Nostrand-Reinhold Company.

Chemers, M. M., Hu, L. T., \& Garcia, B. F. (2001). Academic self-efficacy and first-year college student performance and adjustment. Journal of Educational Psychology, 93, 5564.

Cohen, J. (1988). Statistical power analysis for the behavioral sciences. (2 ${ }^{\text {nd }}$ ed.). Hillsdale, New Jersey: Lawrence Erlbaum.

Conroy, D. E., \& Elliot, A. J. (2004). Fear of failure and achievement goals in sport: Addressing the issue of the chicken and the egg. Anxiety, Stress, and Coping, 17, 271-285.

Corno, L. (1993). The best-laid plans: Modern conceptions of volition and educational research. Educational Researcher, 22, 14-22.

Corno, L. (2004). Introduction to the special issue work habits and work styles: Volition in education. Teachers College Record, 106, 1669-1694.

Corno, L., \& Kanfer, R. (1993). The role of volition in learning and performance. Review of Research in Education, 19, 301-341.

Crowne, D. P., \& Marlowe, D. (1960). A new scale of social desirability independent of psychopathology. Journal of Consulting Psychology, 24, 349-354. 
Dewitte, S., \& Lens, W. (1999). Volition: Use with measure. Learning and Individual Differences, 11, 321-333.

Draper, N. R., \& Smith, H. (1998). Applied regression analysis. (3 ${ }^{\text {rd }}$ edition). New York: Wiley.

Eissa, M. A. (2009). The effectiveness of a program based on self-regulated strategy development on the writing skills of writing-disabled secondary school students. Electronic Journal of Research in Educational Psychology, 17, 7(1), 5-24.

Elliot, A. J. (1997). Integrating the "classic" and "contemporary" approaches to achievement motivation: A hierarchical model of approach and avoidance achievement motivation. In P. Pintrich \& M. Maehr (Eds.), Advances in motivation and achievement (Vol. 10, pp. 143-179). Greenwich, CT: JAI Press.

Elliot, A. J., \& Church, M. A. (1997). A hierarchical model of approach and avoidance achievement motivation. Journal of Personality and Social Psychology, 72, 218-232.

Elliot, A. J., \& McGregor, H. A. (1999). Test anxiety and the hierarchical model of approach and avoidance achievement motivation. Journal of Personality and Social Psychology, $76,628-644$.

Elliot, A. J., \& McGregor, H. A. (2001). A 2 x 2 achievement goal framework. Journal of Personality and Social Psychology, 80, 501-519.

Field, A. P. (2005). Discovering statistics using SPSS. ( $2^{\text {nd }}$ edition). London: Sage.

Freund, R. J., \& Wilson, W. J. (1998). Regression analysis: Statistical modeling of a response variable. San Diego, CA: Academic Press.

Gable, S., Reis, H., \& Elliot, A. J. (2003). Evidence for bivariate systems: An empirical test of appetition and aversion across domains. Journal of Research in Personality, 37, 349372.

Garcia, T., McCann, E. J., Turner, J. E., \& Roska, L. (1998). Modeling the mediating role of volition in the learning process. Contemporary Educational Psychology, 23, 392-418.

Grove, W. A., Wasserman, T., \& Grodner, A. (2006). Choosing a proxy for academic aptitude. Journal of Economic Education, 37, 131-147.

Harackiewicz, J. M., Barron, K. E., Pintrich, P. R., Elliot, A. J., \& Thrash, T. M. (2002). Revision of achievement goal theory: Necessary and illuminating. Journal of Educational Psychology, 94, 638-645.

Herman, W. E. (1990). Fear of Failure as a distinctive personality trait measure of test anxiety. Journal of Research and Development in Education, 23, 180-185. 
Kehr, H. M. (2004). Implicit/explicit motive discrepancies and volitional discrepancies and volitional depletion among mangers. Personality and Social Psychology Bulletin, 30, 315-327.

Kuhl, J. (1987). Action control: The maintenance of motivational states. In F. Halisch \& J. Kuhl (Eds.), Motivation, intention, and volition (pp. 279-291). Berlin: SpringerVerlag.

Kuhl, J. (2000). A functional-design approach to motivation and self-regulation: The dynamics of personality systems interactions. In M. Boekaerts, P. R. Pintrich, \& M. Zeidner (Eds.). Handbook of Self-regulation (pp. 111-169). San Diego, CA: Academic Press.

Ley, K., \& Young, D. B. (1998). Self-regulation behaviors in underprepared (developmental) and regular admission college students. Contemporary Educational Psychology, 23, 42-64.

McCann, E. J., \& Garcia, T. (1999). Maintaining motivation and regulating emotion: Measuring individual differences in academic volitional strategies. Individual Differences Research, 11, 259-279.

McCann, E. J., \& Turner, J. E. (2004). Increasing student learning through volitional control. Teachers College Record, 106, 1695-1714.

McClelland, D. C., Atkinson, J. W., Clark, R. A., \& Lowell, E. L. (1953). The achievement motive. New York: Appleton-Century-Crofts.

McGregor, H. A., \& Elliot, A. J. (2005). The shame of failure: Examining the link between fear of failure and shame. Personality and Social Psychology Bulletin, 31, 218-231.

Multon, K. D., Brown, S. D., \& Lent, R. W. (1991). Relation of self-efficacy beliefs to academic outcomes: A meta-analytic investigation. Journal of Counseling Psychology, $38,30-38$.

Pintrich, P. R. (2000). Multiple goals, multiple pathways: The role of goal orientation in learning and achievement. Journal of Educational Psychology, 92, 544-555.

Pintrich, P. R. (2004). A conceptual framework for assessing motivation and self-regulated learning in college students. Educational Psychology Review, 16, 385-407.

Pintrich, P. R., Smith, D., Garcia, T, McKeachie, W. J. (1991). A manual for the use of the Motivated Strategies for Learning Questionnaire (MSLQ). Ann Arbor, MI: National Center for Research to Improve Postsecondary Teaching and Learning, University of Michigan. 
Pintrich, P. R., Smith, D., Garcia, T, McKeachie, W. J. (1993). Reliability and predictive validity of the Motivated Strategies for Learning Questionnaire (MSLQ). Educational and Psychological Measurement, 53, 801- 813.

Reynolds, W. M. (1982). Development of reliable and short forms of the Marlowe-Crowne Social Desirability Scale. Journal of Clinical Psychology, 38, 119-125.

Stamps, L. W. (1973). The effects of intervention techniques on children's fear of failure behavior. The Journal of Genetic Psychology, 123, 85-97.

Thill, E. E., \& Cury, F. (2000). Learning to play golf under different goal conditions: Their effects on irrelevant thoughts on subsequent control strategies. European Journal of Social Psychology, 30, 101-122.

Thrash, T. M., \& Hurst, A. L. (2008). Approach and avoidance motivation in the achievement domain: Integrating the achievement motive and achievement goal traditions. In A. E1liot (Ed.), Handbook of approach and avoidance motivation (pp. 217-233). New York: Taylor \& Francis.

Torrano, F. M., \& González, M. (2004). Self-regulated learning: Current and future directions. Electronic Journal of Research in Educational Psychology, 2(1), 1-34.

Trawick, L., \& Corno, L. (1995). Expanding the volitional resources of urban community college students. In P. Pintrich (Ed.), Understanding self-regulated learning (pp. 5770). San Francisco, CA: Jossey-Bass.

Tuckman, B. W. (2003). The effect of learning and motivation strategies training on college students' achievement. Journal of College Student Development, 44, 430-437.

Turner, J. C., Thorpe, P. K., \& Meyer, D. K. (1998). Students' reports of motivation and negative affect: A theoretical and empirical analysis. Journal of Educational Psychology, 90, 758-771.

Weinstein, C. E., \& Mayer, R. (1986). The teaching of learning strategies. In M. C. Wittrock (Ed.), Handbook of research $n$ teaching ( $3^{\text {rd }}$ ed.) (pp. 315-327). New York: Macmillan.

Wolters, C. A. (1998). Self-regulated learning and college students' regulation of motivation. Journal of Educational Psychology, 90, 224-235.

Wolters, C. A. (1999). The regulation between high school students' motivational regulation and their use of learning strategies, effort, and classroom performance. Learning and Individual Differences, 11, 281-299.

Wolter, C. A. (2003). Regulation of motivation: Evaluating an underemphasized aspect of self-regulated learning. Educational Psychologist, 38, 189-205. Wolters, C. A. (2004). Advancing achievement goal theory: Using goal structures and goal orientations to 
predict students' motivation, cognition, and achievement. Journal of Educational Psychology, 96, 236-250.

Wolters, C. A., \& Rosenthal, H. (2000). The relation between students' motivational beliefs and their use of motivational regulation strategies. International Journal of Educational Research, 33, 801-820.

Van Yperen, N. W. (2006). A novel approach to assessing achievement goals in the context of the $2 \times 2$ framework: Identifying distinct profiles of individuals with different dominant achievement goals. Personality and Social Psychology Bulletin, 32, 1432-1445.

Zimmerman, B. (2000). Self-efficacy: An essential motivate to learn. Contemporary Educational Psychology, 25, 82-91. 